\title{
DOIS MODOS DE CONSTRUÇÃO DA POSIÇÃO SUJEITO-LEITOR: UMA ANÁLISE DISCURSIVA DA LINGUAGEM JORNALÍSTICA DOS JORNAIS DIÁRIO CATARINENSE E HORA DE SANTA CATARINA
}

\author{
TWO WAYS OF CONSTRUCTING THE READER 'S SUBJECT POSITION: A \\ DISCURSIVE ANALYSIS OF THE NEWSPAPER LANGUAGE OF THE NEWSPAPERS \\ DIÁRIO CATARINENSE AND HORA DE SANTA CATARINA
}

Submetido em: 01-03-2011

Publicado em:23-02- 2013

Sandro Braga ${ }^{1}$

san15@ig.com.br

UNISUL - Universidade do Sul de Santa Catarina Programa de Pós-graduação em Ciências da Linguagem

Fabiana Osvaldete dos Santos ${ }^{2}$

\begin{abstract}
Resumo: Analisamos, com base na Análise do Discurso de corrente francesa, como os jornais Diário Catarinense e Hora de Santa Catarina produzem distintas posições de sujeitoleitor. A justificativa deste artigo baseia-se no fato de os dois jornais serem produtos de uma mesma empresa de comunicação. Partiu-se da hipótese de que haveria, no mercado, dois perfis de leitores, assim, os dois produtos não competiriam entre si, mas complementar-seiam na cobertura de uma região de leitura. A leitura, aqui, é tratada como um processo de produção de efeitos de sentido. Para isso, pautamo-nos no pensamento de Orlandi, acerca da concepção de leitura, bem como a distinção entre leitor real e leitor virtual. Apresentamos, também, as pistas contidas nos enunciados, cujas inferências são indispensáveis para a apreensão do dito e do não dito que, por meio de uma análise comparativa, serviu para a compreensão da produção de diferentes posições de sujeito-leitor. A análise aponta que os jornais $D C$ e Hora apresentam características semelhantes quanto ao processo de veiculação de suas informações. No entanto cada veículo se relaciona com seu público alvo de maneiras distintas através do uso da linguagem e no modo de produção de textos noticiosos. Isso acarreta na construção de diferentes posições desses leitores em relação às informações transmitidas, pois se valendo de estratégias enunciativas esses jornais marcam, ideologicamente, os leitores do $D C$ como sendo mais letrados em relação aos do Hora.
\end{abstract}

Palavras-chave: Jornalismo. Discurso. Sujeito-leitor.

Abstract: We analyze, based on French Discourse Analysis, how the newspapers Diário Catarinense and Hora de Santa Catarina produce different reader's subject positions. This research is justified by the fact that both newspapers are products of the same media company. The starting point was the hypothesis that there would be in the market two types of readers, thus the two products do not compete with each other, but they would complement

\footnotetext{
${ }^{1}$ Doutor em Linguística, Professor do Programa de Pós-Graduação em Ciências da Linguagem da Universidade do Sul de Santa Catarina, san15@ig.com.br.

${ }^{2}$ Graduada do Curso de Letra Português/Inglês, bolsista do Programa de Iniciação Científica da UNISUL/ Artigo 170, a_fabi2005@hotmail.com.
}

Work. pap. linguíst., 13(3): 21-44, Florianópolis, out.dez,2012 
each other in the coverage of a reading area. Reading here is treated as a process of production of sense effects. The work is based on Orlandi's thinking about the conception of reading, as well as in the distinction between real and virtual reader. We do also present the clues included in the statements which inferences are essential to apprehend the said and the unsaid which, by means of a comparative analysis, was used to understand the production of different reader's subject position. The analysis points out that the newspapers DC and Hora present similar characteristics in regard to the process of transmitting information, however each newspaper interrelates with its target public in a different way through the use of language and in the manner of production of news. It leads to the construction of different positions of these readers in relation to the information which is transmitted, because, making use of uttering strategies, these newspapers ideologically mark the readers of $D C$ as being more lettered than the ones of Hora.

Keywords: Journalism. Speech. Reader`s subject position.

\section{INTRODUÇÃO}

O presente artigo analisa a posição de sujeito-leitor construída (prevista) nos projetos editoriais de dois jornais de circulação na Grande Florianópolis/SC (Diário Catarinense e Hora de Santa Catarina) ${ }^{3}$ - produtos de uma mesma empresa de comunicação (Grupo Brasil Sul de Comunicação - RBS). Partimos do pressuposto de que haveria no mercado dois perfis de leitores, assim, os dois produtos não competiriam entre si, mas complementar-se-iam na cobertura de uma região de leitura. Nosso enfoque é identificar a posição do sujeito-leitor dos jornais Diário Catarinense e Hora de Santa Catarina, sob a perspectiva da Análise do Discurso. Para tanto, apresentamos algumas dessemelhanças linguísticas encontradas nesses tablóides para que se compreendam as possíveis constituições discursivas propostas para distintos sujeitos-leitores, tendo como corpus 60 exemplares (do DC e do Hora) coletados na periodicidade de $1^{\circ}$ de maio a 30 de junho de 2009.

De partidas chamamos a atenção para a formulação proposta por Michel Pêcheux (1988) e Eni Pulcinelli Orlandi (1996) de que a linguagem não é transparente. Por esse motivo, apontamos nosso interesse no estudo das linguagens constitutivas desses veículos de comunicação, uma vez que o postulado do texto jornalístico é a objetividade e a imparcialidade. Distinguindo as materialidades linguísticas dos dois jornais, partimos da observação de que a linguagem utilizada pelo $D C$ apresenta-se mais próxima à variante culta e ao padrão clássico de escrita jornalística, pautada na referencialidade, enquanto a linguagem do Hora de SC está mais voltada para uma construção coloquial, que caracteriza uma variante de uso menos formal da língua cotidiana. As diferenças não se encerram aí,

\footnotetext{
3 Os jornais Diário Catarinense e Hora de Santa Catarina também são conhecidos e identificados respectivamente pela sigla $D C$ e Hora, assim ora utilizaremos o nome por extenso, ora sua sinonímia.
}

Work. pap. linguíst., 13(3): 21-44, Florianópolis, out.dez,2012 
obviamente. Pelo contrário, é no âmbito linguístico, entendido como processo de multiplicidade de produção de efeitos de sentido, que emerge uma gama de aspectos passíveis de identificação de formações discursivas.

Nossa análise pauta-se ainda nas formulações de Eni Orlandi, sobretudo, em seu texto Discurso e Leitura (1988), bem como nos textos que discutem as relações entre a posição sujeito, o discurso, o texto e a leitura. Desse modo, é por meio da perspectiva do discurso que se inicia, aqui, uma abordagem sobre as possibilidades de leitura e interpretação a partir do reconhecimento de posições de sujeito-leitor distintas.

Para analisarmos as posições-sujeito dos leitores do DC do Hora, investimos neste estudo nos efeitos de sentido produzidos pelos textos destes veículos, ou seja, como eles são compreendidos, como emergem e de que forma eles se movimentam no discurso resultante de processos de leitura. Nosso ponto de partida se dá a partir da própria concepção de discurso que é definido por Michel Pêcheux (1988) como efeitos de sentido entre interlocutores. Dessa forma, o sujeito e os sentidos estão imbricados, considerando que o sujeito se constitui ao produzir sentidos. No entanto, o sentido das palavras, do enunciado, do discurso não é único. Ele não está ligado à sua literalidade, assim, conforme proposto por Orlandi (2007), falar em Efeitos de Sentido é:

[...] compreender a necessidade da ideologia na constituição dos sentidos e dos sujeitos. É da relação regulada historicamente entre muitas formações discursivas que se constituem os diferentes efeitos de sentidos entre locutores. E ainda, falar em efeitos de sentido é pois aceitar que se está sempre no jogo, na relação das diferentes formações discursivas, na relação entre diferentes sentidos. Daí a necessidade do equívoco, do sem-sentido, do sentido 'outro' e, consequentemente, do investimento em 'um' sentido. (ORLANDI, 2007, p. 21)

Ao produzir texto, é natural que o sujeito invista num sentido. Ou seja, aquele que enuncia tem por objetivo que os seus interlocutores apreendam o sentido desejado, uma direção, uma compreensão de forma homogênea. Porém não é o que de fato acontece, os sentidos podem sempre se tornar outros a partir das formações discursivas diferentes em que estão inseridos os discurso, daí é que apontamos a relação direta deste com a ideologia.

Considerando isso, neste estudo apontamos como um mesmo acontecimento factual ao transformar-se em texto noticioso poderá acarretar na construção de diferentes posições de leitores em relação às informações transmitidas. No caso dos jornais $D C$ e Hora, valendo-se 
de estratégias enunciativas, esses veículos marcam, ideologicamente, os leitores do primeiro como sendo mais letrados em relação aos do segundo.

\section{LEITURA}

Adentramos no campo da leitura entendendo essa prática como exercício de atribuição de sentidos e não como capacidade de decodificação de signos linguísticos. Se assim ponderada, a leitura não pode estar dissociada da historicidade. Ou seja, para ler particulares textos há de se considerar todo um contexto social, histórico, cultural, político e econômico no momento da prática dessa atividade. Assim, os textos veiculados nos jornais $D C$ e Hora precisam ser compreendidos sob uma perspectiva histórico-ideológica, já que, permeiam as relações sociais edificadas pelo homem em sua trajetória de vida, marcadas, incisivamente, pelo tempo e lugar de seu registro.

Diante do que foi dito, lança-se um questionamento: como identificar os leitores alvos dos jornais em questão? No intuito de alçar uma resposta mais adequada a essa questão, vejamos, sob o viés da Análise do Discurso, as formas de leitor, conforme propõe Orlandi (2006). Para ela, é possível pensarmos em dois tipos de leitores: o leitor virtual e o leitor real:

Há um leitor virtual inscrito no texto. Um leitor que é constituído no próprio ato da escrita [...] trata-se aqui do leitor imaginário, aquele que o autor imagina (destina) para seu texto e para quem ele se dirige. Tanto pode ser um seu "cúmplice" quanto um seu "adversário" e o leitor real, aquele que lê o texto [...] (ORLANDI, 2006, p. 9).

Para o primeiro leitor, como se observa, é levado em consideração todo um imaginário social; enquanto o segundo leitor, como o próprio nome infere, é real, ou seja, aquele que de fato irá apropriar-se do texto e realizar a leitura, porém em confronto com um leitor mais ou menos idealizado por quem escreveu. Seguindo esse raciocínio, tanto o leitor do $D C$ quanto o leitor do Hora deparam-se com discursos previamente projetados para eles.

Como já mencionado, a linguagem não é algo fixo e passível a decodificação simplesmente. Por meio dela perpassa uma complexidade imensa de significados a que os sujeitos atribuem conforme suas experiências de vida. A leitura, que determinados leitores fazem, envolve um diálogo ininterrupto com outros textos, uma intertextualidade interlocutiva constante. Assim, por mais que se aproxime das intenções de comunidades específicas de leitores, é um processo difícil caracterizar o leitor em sua totalidade.

A resposta para o questionamento que formulamos anteriormente poderia pressupor, em primeiro lugar, o projeto editorial dos jornais DC e Hora, pois, analisando os diferentes públicos, eles alçariam leitores virtuais distintos, visando chamar a atenção desses leitores.

Work. pap. linguíst., 13(3): 21-44, Florianópolis, out.dez,2012 
Sob o ponto de vista dos públicos de cada jornal, caracterizaríamos da seguinte maneira: os leitores do $D C$ são constituídos por um leque de informações diversificadas e pormenorizadas, enquanto os leitores do Hora, por informações mais sintetizadas, considerando, também, as diversificações de editorias, porém voltadas a determinados campos específicos ${ }^{4}$. Nota-se que, em cada um desses dois jornais é possível encontrar uma valorização maior ou menor por determinados assuntos, inclusive no trato da especificidade da matéria jornalística. Por exemplo, no jornal $D C$ as questões políticas nacionais/mundiais ganham bastante espaço e discussão; os artigos críticos se fazem presente com, pelo menos, três textos de autores diferentes; os acontecimentos com temas diversos como: educação, justiça, economia, saúde, entre outros, aparecem de forma constante, enquanto o jornal Hora vale-se mais de assuntos próximos ao entretenimento, concentrando suas matérias num âmbito que parece demandar menos reflexão sobre alguns setores do cotidiano do cidadão. Desse modo, o futebol ganha destaque, assim como o apelo sentimental de leitores com mensagens endereçadas aos seus familiares e/ou relacionamentos amorosos, e, ainda, notícias/imagens sobre celebridades, etc.

Podemos observar, na tabela que segue e no gráfico comparativo, o tratamento dado pelo projeto editorial do Diário Catarinense e do Hora de Santa Catarina, no tangente aos aspectos de uso de cores, variante linguística, espaço para publicidade e, ainda, em relação a editorias específicas, com foco em assuntos nacionais, assuntos locais e futebol.

Quadro 1: Percentagem comparativa da distribuição dos espaços gráficos (DC e Hora)

\begin{tabular}{|l|c|c|}
\hline & Jornal Diário Catarinense & Jornal Hora de Santa Catarina \\
\hline Cores & 9 & 18 \\
\hline Linguagem coloquial & 8 & 15 \\
\hline Assuntos nacionais & 33 & 6 \\
\hline Assuntos locais & 10 & 30 \\
\hline Futebol & 15 & 23 \\
\hline Publicidade & 25 & 8 \\
\hline
\end{tabular}

Figura 1: Gráfico comparativo entre Diário Catarinense e Hora de Santa Catarina.

\footnotetext{
${ }^{4} \mathrm{O}$ termo 'específico', neste caso, não significa especializado, ao contrário disso.
} 


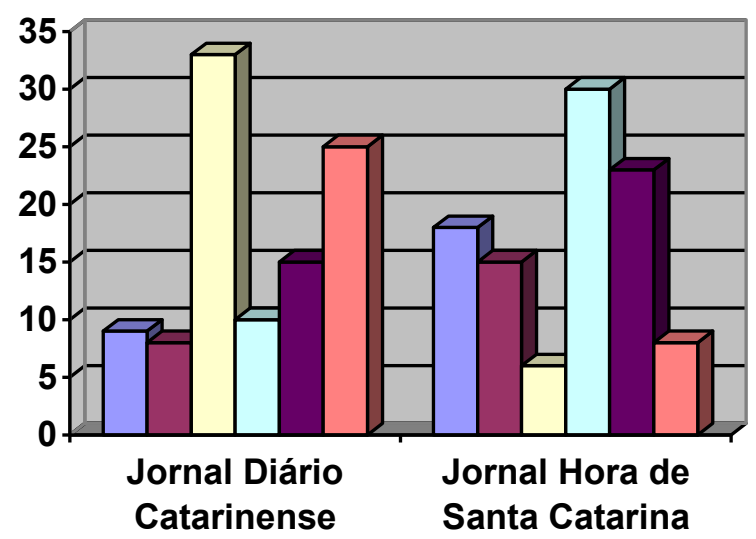

\begin{tabular}{|l|}
\hline$\square$ Cores \\
$\square$ Linguagem coloquial \\
$\square$ Assuntos nacionais \\
$\square$ Assuntos locais \\
$\square$ Futebol \\
$\square$ Publicidade
\end{tabular}

Diante disso, e no intento de ir mais além à caracterização do sujeito-leitor dos referidos jornais, aderirmos à sugestão de Orlandi (2003) sobre as pistas que envolvem o texto, as quais possibilitam adentrar num espaço mais amplo de significação. Essas pistas, primeiramente, precisam ser observadas sob a luz de uma investigação, "para compreender os sentidos aí produzidos, pondo em relação o dizer com sua exterioridade, suas condições de produção.” (ORLANDI, 2003, p. 30) Assim, é de se verificar que tudo o que está, aparentemente, "fora" dos textos transmitidos pelos distintos jornais não o está de todo, visto que o não dito influencia de forma incisiva o que se selecionou para ser dito. Desse modo, a fim de possibilitar maior compreensão concernente à constituição desses leitores, chamamos a atenção para o modo como os espaços físicos desses jornais se apresentam; de que maneira se constituem e quais as ferramentas linguísticas são utilizadas no escopo da persuasão (à leitura). E, para isso, as pistas serão o objeto norteador de direcionamento do objetivo proposto.

\section{NAS LINHAS DO DIZER DO DC E DO HORA}

Observando o jornal Diário Catarinense, verifica-se um espaço bastante diversificado no que diz respeito aos assuntos postos em discussão. Por exemplo, é possível visualizar, constantemente, a veiculação de matérias decorrentes da cobertura de acontecimentos atuais de maior relevância social. Porém, esses fatos não são escolhidos aleatoriamente, mas, e sobretudo, partem de uma posição institucional/empresarial, baseada num processo seletivo de informações. Sabe-se que a escolha de determinados fatos e não de outros, perpassa por toda uma postura ideológica, mas apesar disso, e aceitando a questão da ideologia como

Work. pap. linguíst., 13(3): 21-44, Florianópolis, out.dez,2012 
sendo constitutiva, portanto necessária/inevitável, percebe-se que há, de fato, uma disponibilidade de variação de informações nesse jornal $(D C)$. A título de ilustração, citamos alguns assuntos que ganharam destaque na editoria "Geral": a gripe H1N1, enchentes na Grande Florianópolis; e, em "Variedades": Do classicismo ao Barroco, relembrando a morte de Ayrton Senna.

Com isso, o jornal concede ao leitor uma pluralidade ampla de temas, o que the permite intensificar a reflexão acerca das pautas jornalísticas, mesmo sabendo-se que, ao redigir textos, os redatores não são, em absoluto, imparciais, mas, evidentemente, valem-se de suas subjetividades para escrever e focar o que julgam ser de interesse do leitor. Porém, vale à pena registrar que, no Diário Catarinense, a produção de matérias jornalísticas segue o padrão dos textos jornalísticos, pautados na função referencial da linguagem, caracterizado pela escrita em terceira pessoa, estratégia que, conforme ditam os manuais de redação jornalística, visam à clareza e à objetividade. Essa operação produz, no leitor, uma sensação de isenção da posição do veículo, o que, neste trabalho, temos procurado mostrar que se trata, apenas, de uma estratégia enunciativa, pois não existe discurso (no caso, o texto materializado em notícia) neutro. Esse seria o "jornalismo informativo - gênero supostamente não 'contaminado pela opinião', pela valoração e pela ideologia - define a si mesmo como imparcial e isento". (JACKS; MACHADO, 2001, p. 2).

Já no jornal Hora, é assídua a presença de informações voltadas para os aspectos emotivos, ficando a impressão de aproximação do meio de comunicação (o próprio jornal) e do leitor, numa construção de relação informal e amigável. Por exemplo, o leitor envia questionamentos acerca de inúmeras dúvidas a respeito de assuntos pessoais, como se encontra na coluna do Dr. Batista:

O antitabu! Dr. Batista, sou jovem e ainda sou virgem. E isto me incomoda muito. Não quero mais ser virgem. Procurei a minha ginecologista para perguntar se haveria alguma cirurgia para fazer a retirada de meu hímen, e ela afirmou que sim, que existe um procedimento médico para isto. Gostaria de saber a sua opinião a respeito. Posso fazer? Não terei nenhum problema? Obrigada.

Cara jovem, a retirada cirúrgica do teu hímen em nada te prejudicará. Mas será que é isto mesmo, uma cirurgia, a melhor opção? Se não gostas de ser virgem, tudo bem, mas quem sabe aguarda mais um pouco. Pode aparecer um amigo, um colega, até, por que não, uma paixão, de repente? Não te apressa, tudo tem seu tempo. É interessante este teu caso, pois nos leva a uma reflexão: a que ponto chegamos em nossas regras sociais. Ser virgem, outrora, era uma virtude, hoje é um estigma. Será que está surgindo um outro tipo de preconceito? Ser virgem é careta, é retrocesso, é atraso? Não. E como todo o preconceito, este também deve ser inaceitável. [SIC] (HORA DE SANTA CATARINA. 15/06/2009, p.18).

Work. pap. linguíst., 13(3): 21-44, Florianópolis, out.dez,2012 
Verifica-se que o leitor proposto pelo Hora deve se sentir muito mais à vontade para expor seus pensamentos, dificuldades e alegrias. No que concerne ao aparato gráfico, o jornal é planejado com textos mais curtos e delimitados, o que, de certo modo, retira uma possível complexidade do assunto, produzindo, assim, a impressão de uma leitura única, já interpretada, colocando o leitor numa posição de um sujeito-leitor passivo. Isso dito, esse leitor encontra um ambiente propício para uma maior aceitação do que é veiculado e, consequentemente, é impedido de realizar inferências sobre os textos em foco. Além disso, ele também se depara com uma forma de transmissão de informações mais confortável, por ser levado a não questionar a posição assumida pelo veículo.

4 AS POSSIBILIDADES DO PROCESSO DE SIGNIFICAR

Nas palavras de Dominique Maingueneau (2001), fica explícito que o processo de compreensão e significação de enunciados é muito mais complexo do que se supõe ser, ou seja, para se atribuir sentido não basta a materialidade significante em que as palavras estão inseridas, por determinadas instâncias, é preciso ir além da consideração de um mero contexto circundante ao texto. Com isso, "todo ato de enunciação é fundamentalmente assimétrico" (MAINGUENEAU, 2001, p. 20). Dito de outro modo, o resultado da interpretação de enunciados considera o contexto, todavia pode não corresponder ao que o enunciador deseja transmitir (o efeito de sentido pretendido).

Compreender um enunciado não é somente referir-se a uma gramática e a um dicionário, é mobilizar saberes muito diversos, fazer hipóteses, raciocinar, construindo um contexto que não é um dado preestabelecido e estável. (MAINGUENEAU, 2001, p. 20).

Considerando essa complexidade, os leitores dos referidos jornais ativam dispositivos subjetivos no trabalho de leitura dos textos apresentados. Por exemplo, no dia 14/06/09, o Hora publicou, em "Seu problema é nosso", uma notícia com o título: "Aterro em Biguaçu até parece um lixão", e na sequência o resumo: "Local onde serão construídas instalações dos Bombeiros e PM recebe entulhos e atrai bichos. Prefeitura garante que ninguém mais vai jogar lixo lá". Tanto o título quanto o resumo apresentam ao leitor informações que possibilitam realizar diversas inferências, a saber:

- o lixo não está sendo jogado em qualquer lugar, ele está sendo despejado em um local programado para o assentamento de instituições públicas - Bombeiros (B) e Polícia Militar (PM);

- essas instituições aparecem em uma hierárquica pirâmide de controle social, em posições bastante privilegiadas, pois possuem caráter de segurança, de proteção, de ordem; 
- a comparação sensacionalista do título faz parecer que, por causa de mais esse "descaso de muitos", ao contribuírem com a poluição, torna necessária a implantação, cada vez mais assídua, de instituições como B e PM;

- ao afirmar que a prefeitura resolverá o problema, é possível julgar o prefeito atual como bom gestor, pois está visando ao cuidado de um bem maior para a população e, ainda, registra-se que o uso do termo garante não aponta para uma intenção ou promessa da prefeitura, mas para uma ação que resultará na resolução do problema;

- o título produz sentimento de indignação e susto, já o resumo, de conforto. O primeiro lança o problema e o segundo o resolve.

Indubitavelmente, outras inferências poderão ser emitidas pelos leitores, isso porque cada pessoa dispõe de singulares experiências de vida, tornando-a única e, por isso, com particulares visões de mundo. Contudo, trazemos essas possibilidades de implicações subentendidas lembrando as palavras de Maingueneau (2001), quando diz ser extremamente complexo o processo de formação de significados que uma pessoa faz ao deparar-se com os mais diferentes enunciados. $\mathrm{O}$ autor ainda menciona a presença de três competências, relevantes ao desenvolvimento interpretativo: competência enciclopédica - conhecimento de mundo, competência comunicativa - produção e interpretação e competência linguística referente à língua. Essas competências são construídas, segundo o autor, por intermédio de impregnação, quer dizer, na constante tarefa, consciente ou inconsciente, de aprendizagem, na convivência com o outro, na recepção de inúmeras informações. Elas não são independentes umas das outras, mas, ao ativar as três competências, adquire-se maior compreensão dos enunciados.

Outra matéria do Hora, que trata acerca da desenvoltura de um time de futebol em campo, temos o seguinte enunciado: "Figueirense fez uma péssima partida em Goiânia e perdeu para Atlético-GO por 3 a 2. Wilsom falhou feio e Rafael Coelho perdeu pênalti". Nesse segmento linguístico, ressaltamos o uso de duas palavras: péssima e feio. Esse enunciado procura chamar a atenção do leitor, como se ele identificasse seu próprio modo de falar no dizer do jornalista. Isso parece se confirmar com as palavras destacadas, haja vista que um torcedor de futebol, geralmente, sente a necessidade de exprimir seu contento ou descontentamento com o time pelo qual é torcedor. Assim, o termo péssima assume no enunciado a função de adjetivo enquanto feio a de advérbio, agindo sobre o modo asseguram, fortalecem o leitor em sua posição, fazendo com que esse leitor admita tal enunciado como legítimo.

Work. pap. linguíst., 13(3): 21-44, Florianópolis, out.dez,2012 
O texto não se destina a ser contemplado, configurando-se como enunciação dirigida a um co-enunciador que é preciso mobilizar, fazê-lo aderir "fisicamente" a um determinado universo de sentido. O poder de persuasão de um discurso consiste em parte em levar o leitor a se identificar com a movimentação de um corpo investido de valores socialmente especificado. (MAINGUENEAU, 2001, p. 99, grifos do autor).

Por outro lado, tais palavras parecem bloquear qualquer julgamento outro que não seja negativo. Elas atuam como círculo e não como labirinto, no sentido de impedir a construção de hipóteses e levando o leitor a ser absoluto e unilateral. Tudo isso aliado aos elementos linguísticos, fornecedores de pistas de significação, trabalham em conjunto no intento de produzir determinados efeitos de sentido.

No Hora, por exemplo, é comum as notícias serem escritas com uma estrutura diferenciada dos tablóides tradicionais, sendo o texto dividido em colunas menores, de forma, aparentemente, não harmônica, para facilitar a leitura para um tipo de público que não tem o hábito de ler, ou que está sempre com pressa, correndo, sem tempo para essa leitura. As cores também são um elemento forte nesse veículo, predominando o verde claro e escuro. Isso porque, qualquer cor, diferente da preta e branca, parece ser mais atrativa. Os resumos, as chamadas e os títulos estão sempre ou em negrito ou em quadros com fundo verde. Os discursos diretos também marcam bastante presença junto a vocábulos e/ou expressões de caráter oral. Exemplo disso pode ser observado no relato de um entrevistado em pequena reportagem sobre o uso de telefone móvel por pessoas de mais idade:

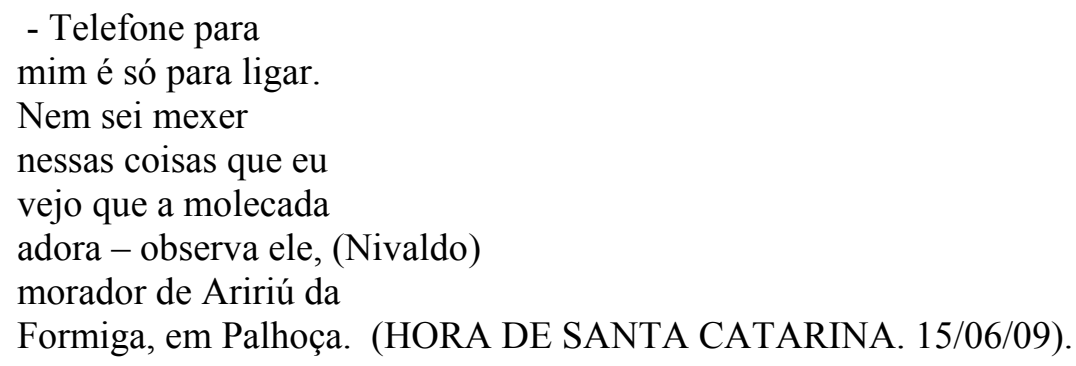

O texto foi transcrito, obedecendo a mesma diagramação de publicação no jornal Hora. Trata-se de um discurso direto, com uma linguagem informal e de maneira desarmônica quanto sua estrutura formal de língua. O efeito da exemplificação busca mostrar que muitas pessoas, como o entrevistado Nivaldo, possuem a mesma dificuldade em manusear um aparelho telefônico móvel (sobretudo os mais recentes lançamentos), assim, o discurso desse cidadão/entrevistado (leitor potencial) não é apenas dele, mas de um conjunto

Work. pap. linguíst., 13(3): 21-44, Florianópolis, out.dez,2012 
de leitores, provavelmente com a mesma faixa etária, que compartilham do mesmo pensamento e da mesma dificuldade em relação ao uso do aparelho.

Já o Diário Catarinense, diferentemente do Hora de Santa Catarina, apresenta enunciados que, à primeira vista, distanciam-se de uma visão mais opinativa. A chamada da notícia que segue foi publicada no $D C$ dia 14/06/09, na seção "Política", trazendo em si um assunto de relevância social e propulsor de polêmica:

A proposta de ementa constitucional (PEC) que prevê referendo sobre a possibilidade do presidente Luiz Inácio Lula da Silva concorrer a um terceiro mandato é assunto que, apesar de polêmico, deixou de ser apenas uma tese. A proposta está tramitando - e em tese teria apoio considerável, pelo menos na Câmara federal (DIÁRIO CATARINENSE).

Maingueneau (2001) fala do que chama de princípio de cooperação. Esse princípio considera um acordo entre duas partes: redator e leitor; um acordo mútuo de respeito no exercício da troca verbal. Aplicando essa compreensão, diríamos que o leitor do $D C$ valoriza o enunciado por afigurar-se uma importante discussão sobre a vida social brasileira. Isso dito, autor respeita leitor e vice e versa. Além do conteúdo, destaca-se o semantismo das palavras proposta e possibilidade, sugerindo algo que ainda não foi decidido, mas passível de aprovação. Com isso, ao leitor é dada a possibilidade de refletir sobre uma posição; tal assunto, antes, era apenas uma tese, agora torna necessária uma investigação acerca do que poderá ser legitimado, pois delega, ao atual presidente, muito poder; o verbo teria, apesar de estar flexionado no futuro do pretérito, não assinala ação futura não acontecida e, sim, produz um caráter de aspecto que indica uma suposição.

Torna-se difícil afirmar a existência de algum enunciado que não respeite o princípio de cooperação, isso porque, ainda que certos discursos não interessem a uns, podem ser de grande relevância para outros. Muitas pessoas podem se deparar com mensagens não condizentes com suas necessidades ou escolhas, mas isso não significa que não devam ser transmitidas. Ainda, a respeito do texto em questão, o $D C$ apresenta um quadro, na sequência da reportagem, intitulado "Opiniões", em que estão expostas as falas de um prefeito, dois deputados e um ministro. Observemos duas dessas opiniões para fins de análise, a saber:

Deputado Federal Décio Lima (PT), único catarinense que assinou a proposta que está tramitando na Câmara: "Sou favorável que haja quantos mandatos forem necessários enquanto nós não fizermos uma reforma do Estado" (DIÁRIO CATARINENSE, grifos nosso). 
Ministro Gilmar Mendes, presidente do STF: "O terceiro mandato é incompatível com o princípio republicano e o princípio federativo do país" (DIÁRIO CATARINENSE, grifos nosso).

A primeira, como se vê, emite uma visão positiva quanto ao terceiro mandato de Lula, já a segunda, não. Todavia, as duas posições não são contra ou a favor simplesmente. Elas emitem argumentos, os quais fundamentam suas posições. Com isso, ao leitor do $D C$ são endereçados subsídios para uma reflexão do assunto tema da polêmica. Aqui, diferentemente de um caminho circular de leitura, prevalece o do labirinto, ou seja, os inúmeros trajetos que um leitor pode percorrer até chegar a um ponto X, porém sendo posto numa posição em que se sente impelido a escolher esse percurso. Dessa forma, o leitor, ao interpretar essas opiniões acopladas de informações, produz relações com seu repertório de mundo que o levará a aceitar a opinião de $\mathrm{X}$ e de $\mathrm{Y}$ e refutar a opinião de $\mathrm{W}$ e de $\mathrm{Z}$.

\section{UM COTEJO REFLEXIVO}

A seguir passamos a análise de recortes de nosso corpus de forma a estabelecer uma comparação ao tratamento dado, a um mesmo fato noticioso, pelo Diário Catarinense e pelo Hora de Santa Catarina.

Iniciamos pelo assunto em pauta nos dois veículos, respectivamente, a visita do presidente Lula à Arábia Saudita, publicado no dia 18/05/2009. Observa-se que para o mesmo assunto, apresentado pelos jornais DC e Hora, houve dessemelhanças significativas, abrindo, a partir desse evento, para a entrada de temas distintos. Assim, nossa proposta, aqui, é examinar a objetividade do tratamento dado ao acontecimento pelos dois jornais no que tange à materialidade linguística por um lado e, por outro, observar os efeitos de sentido produzidos pelo tratamento dado às imagens - a parte não verbal - de maneira a tentar entender a diferenciação de questões como tamanho de imagem, ângulo da fotografia, cor, fonte, entre outros.Vejamos as imagens veiculadas nos dois jornais quando da publicação da matéria em pauta:

Figura 2: Tratamento de imagens fotográficas (Hora e DC)

\begin{tabular}{|l|l} 
Hora de Santa Catarina & Diário Catarinense
\end{tabular}




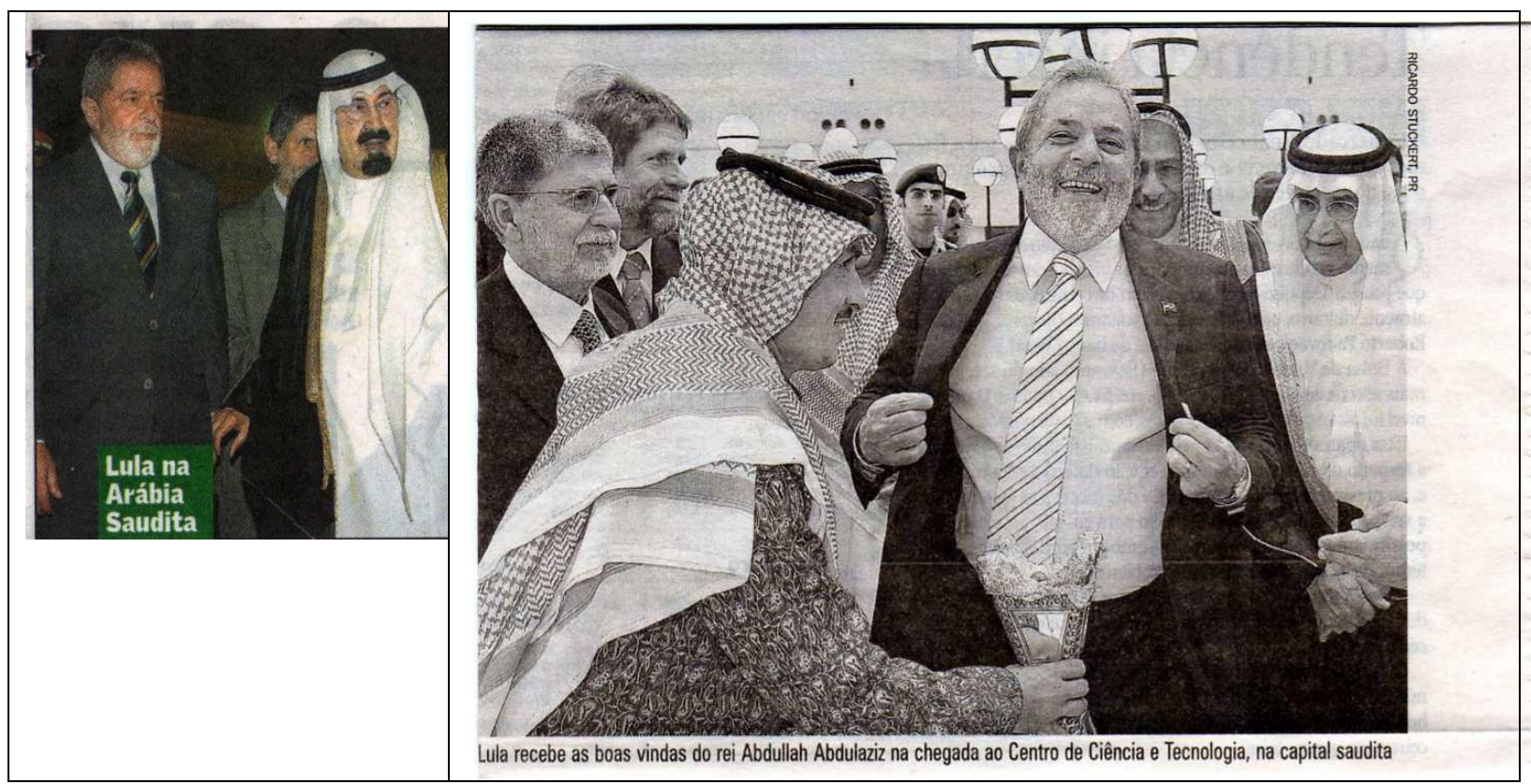

Atentar também para as fotografias, que compõem texto no jornal, compreendendo o texto como unidade multimodal uma vez que se constitui na junção entre a dimensão imagética não verbal e a dimensão verbal, pode auxiliar na compreensão da rede de significação que atua na produção dos efeitos de sentido.
A análise do discurso defende a idéia de que qualquer imagem, mesmo isolada de qualquer outro sistema semiótico, deve sempre ser considerada como sendo um discurso, recusando a categoria de "signos icônicos" ou "ícones" em que são em geral classificadas pelos semiólogos (PINTO, 2002 , p. 37 , grifos do autor).

Como já dito, as notícias (do DC e do Hora) foram transmitidas no dia 18/05/2009 e abordam um tema relacionado à viagem do presidente Lula para a Arábia Saudita. No que diz respeito ao não verbal, o Hora apresenta uma imagem - Lula ao lado do rei saudita Abdullan - menor e colorida, diferentemente do $D C$, cujas cores estão em preto e branco e em tamanho duas vezes maior. Ainda na foto do $D C$, percebe-se que o ângulo de abertura da foto permite uma visão mais ampla, incluindo, nesse campo, a presença de outras personagens tanto do cenário político do Brasil e da Arábia quanto à presença de militares daquele país - soldados ao fundo - que permite uma interpretação de como são tratados os assuntos de segurança nacional na Arábia Saudita. Seguindo a comparação, observemos as legendas em ambas as fotos: No $D C$ temos "Lula recebe as boas vindas do rei Abdullan Abdulaziz na chegada ao Centro de Ciências e Tecnologia, na capital saudita; e no Hora "Lula na Arábia Saudita". Além da quantidade de caracteres usados na construção dessas escritas - uma mais extensa

Work. pap. linguíst., 13(3): 21-44, Florianópolis, out.dez,2012 
outra mais sintética - podemos questionar: quais os efeitos de sentidos essas sentenças produzem? Qual a relação dessas informações com o fato noticiado? Qual é o foco de cada legenda? E mais, o que elas querem informar aos seus respectivos leitores? E ainda, o que é silenciado num e noutro veículo? De saída, é possível chamar a atenção para construção sintática dessas legendas. Na primeira legenda $(D C)$ a frase denota que "Lula recebe as boas vindas do rei" [...] é análogo a uma sentença construída na voz passiva, ou seja, o sujeito Lula é quem recebe essa ação do rei que lhe dá boas vindas. Dito de outro modo, o foco é o Lula, mas a construção é mais complexa, pois envolve outra ação. Já no Hora, a sentença "Lula na Arábia Saudita" é uma frase mais simples, em termos de estrutura sintática. Nota-se que não há verbo, a ligação de "Lula" a um lugar específico se dá através de uma preposição "na" (em + a). Poderíamos, nesse caso, construir uma paráfrase para essa legenda em que teríamos "Lula está na Arábia Saudita"; agora, nesta sentença há a presença do o verbo “estar”, mas que, também, não funciona como um verbo de movimento, ao contrário, é um verbo de ligação. Em síntese, podemos dizer que a primeira legenda leva o leitor a um campo de significação em que está em cena o presidente do Brasil e suas relações com a política externa, enquanto a segunda mostra o presidente fora do Brasil, o presidente na Arábia ou, ainda, o presidente viajando.

Esses eventos não estão diferenciados casualmente, mas revelam formações discursivas (a partir de formações ideológicas específicas) relevantes na constituição de cada sujeito-leitor. Por exemplo, por que o texto do $D C$ enfatiza mais as questões de comércio entre Brasil e Arábia Saudita e, o texto do Hora, ressalta o descontentamento de Lula com a instauração de uma CPI para investigar a competência administrativa da Petrobrás? Mesmo chamando a atenção do leitor com uma foto em cores, parece-nos conveniente pensar que, para o leitor do Hora, não está previsto assuntos de cunho da política externa, como, também, pontuamos na análise da legenda. Assim, o texto deve focar um assunto que diga respeito a uma factualidade do cenário nacional. Nessa perspectiva, o sentido sempre pode ser outro, mas não pode ser qualquer um, há sempre uma relação com a posição em que o sujeito se encontra, como podemos perceber nos termo de Orlandi,

De acordo com a análise do discurso, o sentido não existe em si mas é determinado pelas posições ideológicas colocadas em jogo no processo sócio-histórico em que as palavras são produzidas. As palavras mudam de sentido segundo as posições daqueles que as empregam. Elas tiram seu sentido dessas posições, isto é, em relação às formações ideológicas nas quais essas posições se inscrevem. [...] Uma palavra recebe seu sentido na 
relação com as outras da mesma formação discursiva e o sujeito-falante aí se reconhece (ORLANDI, 2006, p. 58).

Já no $D C$ a imagem é apresentada em preto e branco, ainda que seja maior, conjectura-se que o leitor desse jornal não precisa ser estimulado com cores para ler o assunto em pauta, mas ele deve ser orientado a como interpretar. Percebe-se que, em vez de discutir acerca da CPI, a matéria jornalística do $D C$ explana, detalhadamente, a estada de Lula na Arábia Saudita, bem como enfatiza os benefícios comerciais que poderão ser conquistados com um acordo entre os dois países. Outrossim, na imagem do $D C$, Lula aparece com sorriso bastante expressivo. Considerando as características mencionadas desse jornal, percebe-se o discurso do $D C$ (tanto na materialidade linguística quanto imagética) contendo uma ideologia que perpassa a forma de escrita do texto e a maneira como as pessoas estão dispostas nas imagens. Aqui, o leitor poderá ser levado a concluir que um acordo entre os dois países será, economicamente, salutar ao Brasil. Na sequência, os enunciados e os termos/expressões-chave que corroboram nossa análise:

Quadro 3: Escolha lexical do jornal Diário Catarinense

\begin{tabular}{|c|c|}
\hline ENUNCIADO & $\begin{array}{l}\text { TERMOS e/ou } \\
\text { EXPRESSÕES-CHAVE }\end{array}$ \\
\hline $\begin{array}{l}\text { A visita do presidente Luiz Inácio Lula Da Silva à Arábia Saudita } \\
\text { “destravou” as negociações para um acordo de livre comércio } \\
\text { entre o Mercosul e as nações do Conselho de cooperação do } \\
\text { Golfo. }\end{array}$ & Destravou \\
\hline $\begin{array}{l}\text { Lula reforçou a intenção de estimular as trocas comerciais entre } \\
\text { os dois países - que aumentaram mais de } \mathbf{7 0 \%} \text { entre } 2007 \text { e } \\
2008 \text {. }\end{array}$ & $\begin{array}{l}\text { aumentaram mais de } \\
70 \%\end{array}$ \\
\hline $\begin{array}{l}\text { Um bem sucedido acordo entre o Mercosul e o Conselho de } \\
\text { Cooperação do Golfo... }\end{array}$ & bem sucedido \\
\hline $\begin{array}{l}\text { *Além disso, todo o discurso está envolto de cordialidade para } \\
\text { com o presidente Lula. }\end{array}$ & $\begin{array}{l}\text { * Um jantar oferecido a } \\
\text { Lula pelo rei... }\end{array}$ \\
\hline $\begin{array}{l}\text { O presidente e o rei discutiram a atualidade política da América } \\
\text { Latina... }\end{array}$ & $\begin{array}{l}\text { * Reunião bilateral. } \\
\text { * Trocaram elogios sobre } \\
\text { o processo de paz. }\end{array}$ \\
\hline
\end{tabular}

As palavras destacadas, na segunda coluna, apresentam-nos um panorama bastante positivo, quase que inquestionável, quanto à visita de Lula naquele país. Fica, para o leitor do $D C$, a certeza da competência do atual presidente, reforçando o que foi dito anteriormente sobre a formação ideológica, a qual é selecionada pelas empresas de informação de acordo com seus projetos editorais. Essas inferências, num primeiro momento, 
não são constatadas, mas, após uma análise mais atenta, torna possível salientar aspectos intrinsecamente ideológicos. Nas palavras de Orlandi:

Na perspectiva de análise do discurso, ao contrário, não há essa liberdade e as marcas que atestam a relação entre sujeito e a linguagem, no texto, não são detectáveis mecânica e empiricamente. Os mecanismos enunciativos não são unívocos nem auto-evidentes. São construções discursivas com seus efeitos de caráter ideológico (ORLANDI, 2006, p. 45).

Outro assunto, em pauta no dia 30/05/2009, sobre o caso de um adolescente suspeito de ter assediado meninas de dez e doze anos, em uma escola no bairro Capoeiras (Florianópolis), serve, também, para apontar com se dá a construção do sujeito-leitor nos jornais em questão. No $D C$, temos uma imagem maior e em preto e branco já, no Hora, temos uma imagem menor e colorida, porém trata-se do mesmo registro fotográfico (uma foto do recente diretor da escola).

Figura 4: Construção e formatação das matérias (DC e Hora)

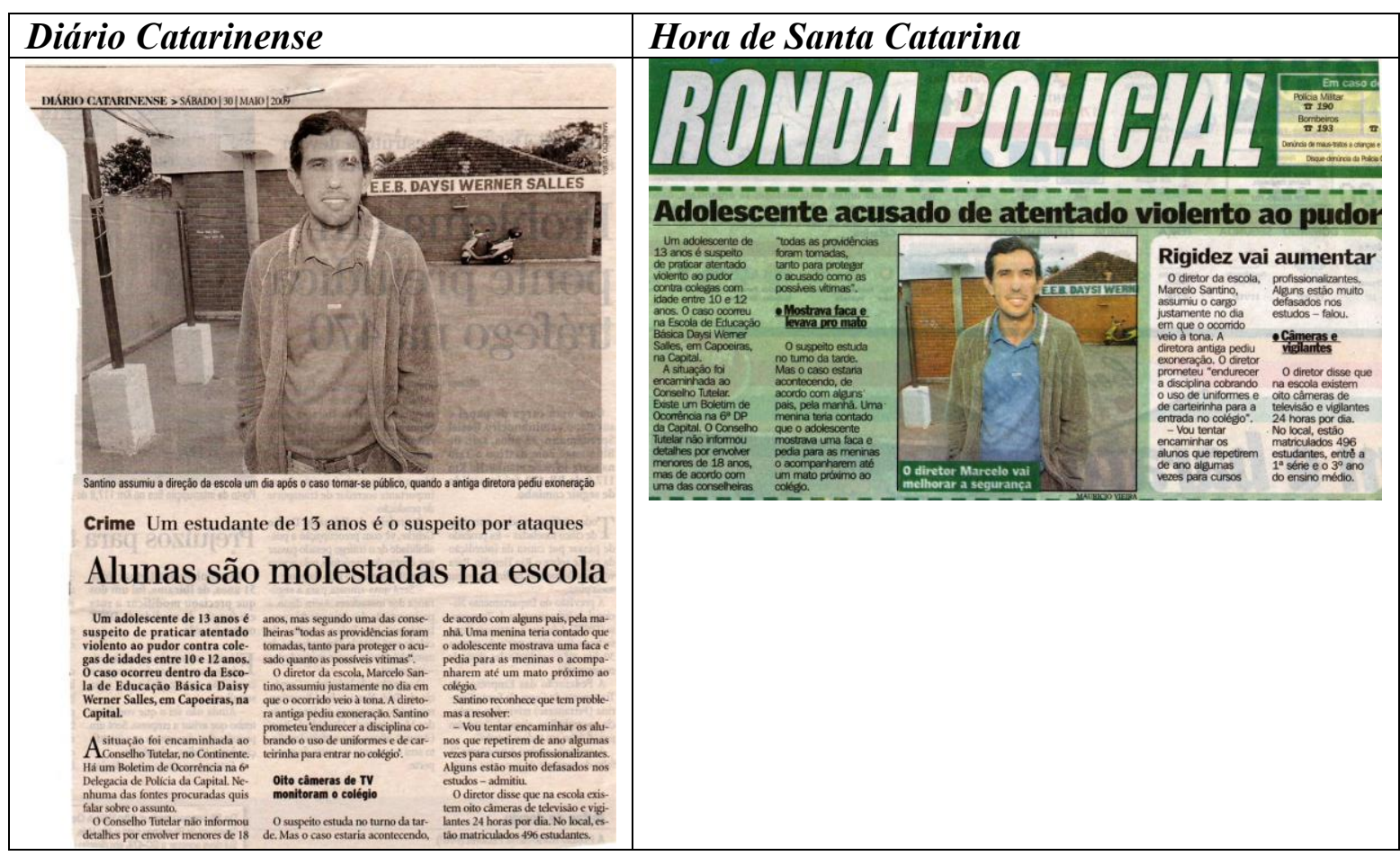

Observemos os diferentes títulos dados à matéria nos respectivos jornais:

$D C$ : “Alunas são molestadas na escola"

Hora: "Adolescente acusado de atentado violento ao pudor".

Temos, nos dois enunciados, um fenômeno denominado Topicalização, em que se desloca o referente que se pretende salientar para o início da frase. No primeiro título, o foco 
está em alunas; no segundo, em adolescentes. Mas, vejamos o que diz as legendas das imagens:

$D C$ : "Santino assumiu a direção da escola um dia após o caso tornar-se público, quando a antiga diretora pediu exoneração.”

Hora: "O diretor Marcelo vai melhorar e segurança."

Diante do que se apresenta, tanto nos títulos quanto nas legendas, é possível fazermos alguns apontamentos. No $D C$, o título, por meio do foco tomado pela topicalização, sugere uma atmosfera, cujos sujeitos são vítimas - sentido expresso pela voz passiva - e dispõe de um léxico eufêmico que abranda (molestada), no decurso da informação, um acontecimento considerado pelo leitor como lastimoso. No Hora, o ambiente é de ação do elemento topicalizado (Adolescente), o qual é descrito de maneira hostilizadora. Valendo-se de léxicos mais contundentes (atentado violento), o jornal põe em evidência a prática do sujeito, bem como uma sentença de "acusação" - mesmo o adolescente tendo sido apenas suspeito e nada provado quanto ao ato.

Em face disso, observa-se que enquanto o $D C$ opta por um léxico que tenta "amenizar" discursivamente a situação reportada, o Hora afigura-se mais taxativo, realizando, dessa forma, um discurso rigoroso e, mais uma vez, inquestionável diante de uma posição das seguranças locais e da administração do recente diretor da escola ao afirmar que ele "vai melhorar a segurança." Isso não quer dizer, entretanto, que o modo de reportar em um jornal é melhor que o do outro, ou que um texto é mais fiel que o outro em ralação ao fato que gerou as matérias. Nem um é melhor porque abranda, pois poderia estar aí ocultando aspectos relevantes, nem outro é melhor porque hostiliza, já que não dispõe da verdade incontestável, nem tampouco tem a função de julgar. Contudo, as formações discursivas pretendem atingir cada público leitor de maneira distinta. Uma buscando um efeito mais "neutralizador", como se pretendesse deixar os fatos falarem por si mesmos (como dito, estratégia da pretensa objetividade), e a outra, se inscrevendo como formadora de opiniões, já que faz afirmações, num primeiro momento.

A relação pragmática entre o enunciador e o destinatário é, em princípio, de distância, imposição, didatismo e superioridade hierárquica: o jornal informa a "verdade" que detém ao leitor passivo e inferior hierarquicamente (PINTO, 2002, p. 97, grifos do autor).

Em outra seção, denominada "Entretenimento", o gênero "horóscopo" é exposto de maneira, também, diferenciada nos dois jornais. 
Figura 5: Seção horóscopo (Hora e DC)

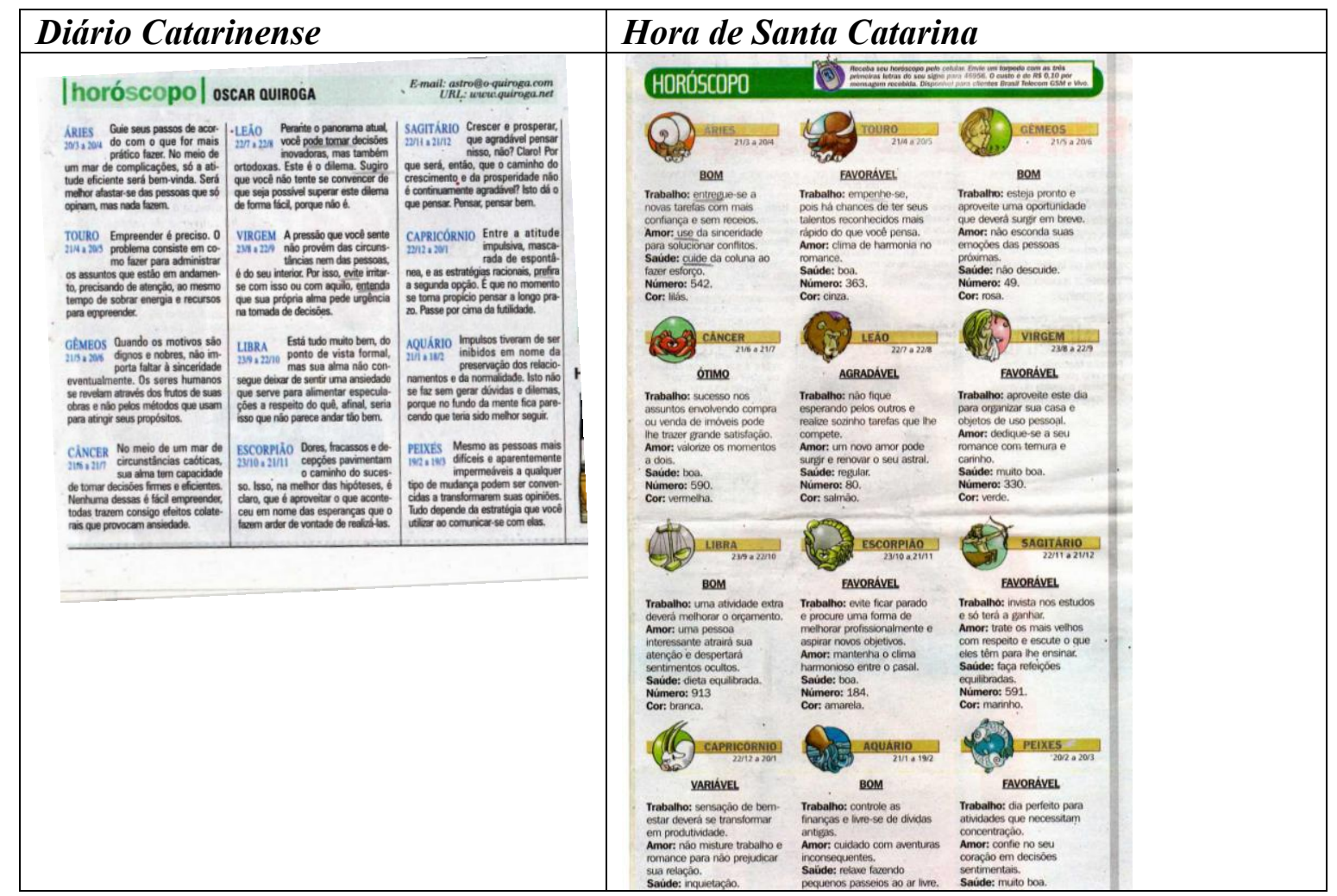

O $D C$ reserva um quarto de uma página e traz o nome do zodíaco (em azul) seguido do texto (em preto) correspondente àquele signo, sem auxílio de ícones gráficos. No corpo de cada texto, encontram-se termos condizentes com uma posição não autoritária, mas de recomendação e aconselhamento, por exemplo: ... você pode tomar decisões inovadoras... (e não você deve), ....sugiro que..., ...evite..., ...entenda ..., ...prefira. A predileção por tais termos possibilita ao leitor uma decisão quanto sua preferência de aderir ou não ao que foi sugerido pelo jornal, que constrói uma imagem amigável e não determinista. Ao passo que, no Hora, esse assunto ocupa dois terços, aproximadamente, de uma página, conferindo bastante importância a esse tipo de informação e/ou, ainda, incutindo em suas páginas o quanto o seu leitor está atrelado às “opiniões dos astros” em relação ao percurso de suas vidas.

Diferentemente do DC, o Hora apresenta cada denominação dos signos vinculados com suas respectivas imagens, ou seja, ilustração (em cores) dos personagens correspondentes ao zodíaco. Além disso, o texto próprio de cada signo apresenta, já de início, um adjetivo que despertará no leitor uma síntese do texto ulterior, o qual é dividido em subtítulos, a saber: Trabalho, Amor, Saúde, Número e Cor, indicando que o leitor desse jornal necessita de tal divisão de tópicos como meio de facilitar (fragmentar) a leitura. Ainda, analisando o corpo do texto, visualizam-se desigual ao modo de disposição das palavras do

Work. pap. linguíst., 13(3): 21-44, Florianópolis, out.dez,2012 
$D C$, léxicos mais vedados, quase todos no modo imperativo de conjugação verbal, como: entregue-se, use, cuide, empenhe-se, esteja pronto, não esconda, não descuide, valorize, não fique esperando, aproveite, dedique-se, mantenha, invista, trate, faça, não misture trabalho..., controle, relaxe, confie, o que caracteriza a função conativa/apelativa da linguagem, aquela que foca o interlocutor no intuito de persuadi-lo.

Em virtude dessas considerações, recorremos ao que diz Pinto (2002) nesse sentido, com o intuito de corroborar a posição, aqui defendida, de constituição do sujeito-leitor do jornal Hora:

[...] sempre infantilizados e avaliados como inferiores intelectualmente, destinatários passivos de um discurso pedagógico, autoritário e arrogante que aquelas entidades (referindo-se aos jornais que analisa) pretendem impor como exclusivos detentores do saber e do poder (PINTO, 2002, p. 63 , grifo nosso).

Mais um exemplo passível de análise, encontra-se veiculado no dia 27/04/2009, nos jornais Diário Catarinense e Hora de Santa Catarina, onde foram noticiadas informações a respeito da campanha de vacinação da gripe $\mathrm{H} 1 \mathrm{~N} 1$ para idosos. O título do $D C$ traz: Mais de 130 mil vacinados, e o do Hora enuncia: 134 mil imunizados. As duas formas de apresentar o assunto, evocando o grande número de pessoas vacinadas, produzem um efeito de sentido quanto ao entendimento da necessidade de se estar resistente fisicamente contra a "nova gripe" que pode ser fatal. Há indicações numéricas, apontando estatísticas que são índices fortes para o convencimento de certas ideologias. Por exemplo, afirmar que 134 mil pessoas foram imunizadas ou vacinadas; que se pretende vacinar/imunizar mais $\mathbf{5 0 6}$ mil idosos; que houve aumento de $\mathbf{4 \%}$ na procura pela vacina; que os vacinados correspondem a $\mathbf{2 2 \%}$ dos cerca de 633 mil idosos; que se pretende vacinar pelo menos $\mathbf{7 5 \%}$ da população idosa é difundir uma ideia, fundamentada em quantitativos, de um trabalho "bem feito" diante da eminência da prevenção contra o vírus H1N1.

Todos esses números, que estão tanto em um jornal quanto em outro, tencionam produzir uma imagem para os sujeitos-leitores de maneira que eles consigam visualizar os benefícios, e persuadir aqueles que são alvo da campanha a aderir ao processo de vacinação. Não existe a imagem negativa, mas, somente, a positiva, do ato imunitário, pois o maior objetivo é fazer com que, nessa fase, se convença a população idosa a se vacinar. Nesse sentido, podemos fazer uma alusão ao pensamento de Foucault, em relação ao dispositivo disciplinar dos sujeitos com fins de controle do poder. 
Enquanto a taxonomia natural se situa sobre o eixo que vai do caráter categoria, a tática disciplinar se situa sobre o eixo que liga o singular e o múltiplo. Ela permite ao mesmo tempo a caracterização do indivíduo como indivíduo, e a colocação em ordem de uma multiplicidade dada. Ela é a condição primeira para o controle e o uso do conjunto de elementos distintos: a microfísica de um poder que poderíamos chamar "celular". (FOUCAULT, 2008, p. 127, grifos do autor).

Dialogando com Foucault, pode-se dizer que o discurso pertencente a essas notícias está atrelado ao poder do Estado, diante da população, com fins disciplinadores e controladores. A vacinação dos idosos contra a gripe H1N1 só está sendo "sugerida" conforme a gravidade estará sendo obrigada - porque existe toda uma intenção política, econômica, cultural, de status, etc., abrangendo esse discurso.

No entanto, há dissimilitudes entre a maneira como cada jornal em questão veicula a importância de tal vacina. Apesar de os textos (notícias) serem bastante semelhantes e contenham trechos completamente iguais, nuances discursivas são percebidas. A imagem (foto) no $D C$, por exemplo, apresenta o rosto de um senhor, colorida, com legenda, em que está escrito o nome dele, no tamanho $3 \times 4$; no Hora a imagem (foto) equivale ao tamanho oito vezes maior, em preto e branco, com uma segunda pessoa - a enfermeira aplicando a vacina; a legenda denota: "Seu Otávio, 93 anos, já garantiu a vacina", nota-se, ainda, o logotipo da Prefeitura Municipal de Florianópolis ao fundo. Diante disso, conjectura-se que, para o leitor do Hora, é preciso tornar visível, imageticamente, a ação de receber a vacina, para um possível aceitamento de recebê-la, pressupondo que o leitor pode ser influenciado pela atitude do outro, especialmente se esse outro pertence ao mesmo grupo que o dele - no caso desse discurso, um idoso servindo de exemplo para outros idosos. "Nas imagens encontramos intertextualidade, enunciadores e dialogismo, tal como nos textos verbais." (PINTO, 2002, p. 37). A logo da prefeitura não aparece por acaso; serve para denotar que o serviço é prestado por um órgão público, portanto gratuito.

$\mathrm{Na}$ legenda também é perceptível, ante a palavra garantiu, uma força intencional, pois tal termo provoca, no leitor, um sentimento de falta de proteção, caso ele ainda não tenha se imunizado, parecendo que o outro, aquele já vacinado, fez sua parte e está seguro, enquanto outros necessitam aderir a esse comportamento. O verbo garantir, nesse contexto, desencadeia uma ação a ser tomada pelo leitor, podendo significar: "corra, você precisa assegurar a sua vacina". Para o mesmo fim, o $D C$ não se vale de todo esse aparato para significar (com recursos de imagens), talvez por julgar prescindível e, também, pelo desejo 
de objetividade e transparência. No Diário o caráter informativo prevalece ao persuasivo, propondo ao leitor a conclusão da necessidade de aderir à campanha.

Cumpre-nos assinalar que autoridades são mencionadas a cada parágrafo com fins de descomprometimento com o que foi dito, delegando qualquer compromisso à Vigilância Epidemiológica do Estado, ao diretor Luiz Antônio da Silva e ao Instituto Brasileiro de Geografia e Estatística (IBGE), os quais, segundo os referidos jornais, são os responsáveis pelas informações que foram transmitidas nessas notícias. Outro aspecto interessante é a presença, no Hora, de uma tabela de informações estruturadas, contendo perguntas e suas respectivas respostas a respeito da vacina $\mathrm{H} 1 \mathrm{~N} 1$. Ao passo que, no $D C$, essas mesmas informações aparecem no corpo do texto. Como se pode notar, ao leitor do Hora, é destinado um texto esmiuçado em fragmentos, bem detalhado, de modo a facilitar sua decodificação. Ao que parece, esse leitor buscará cada vez mais o Hora, pois encontrará informações específicas que atendam as suas necessidades de imediato.

Figura 6: Composição textual das informações verbais e não verbais no Hora

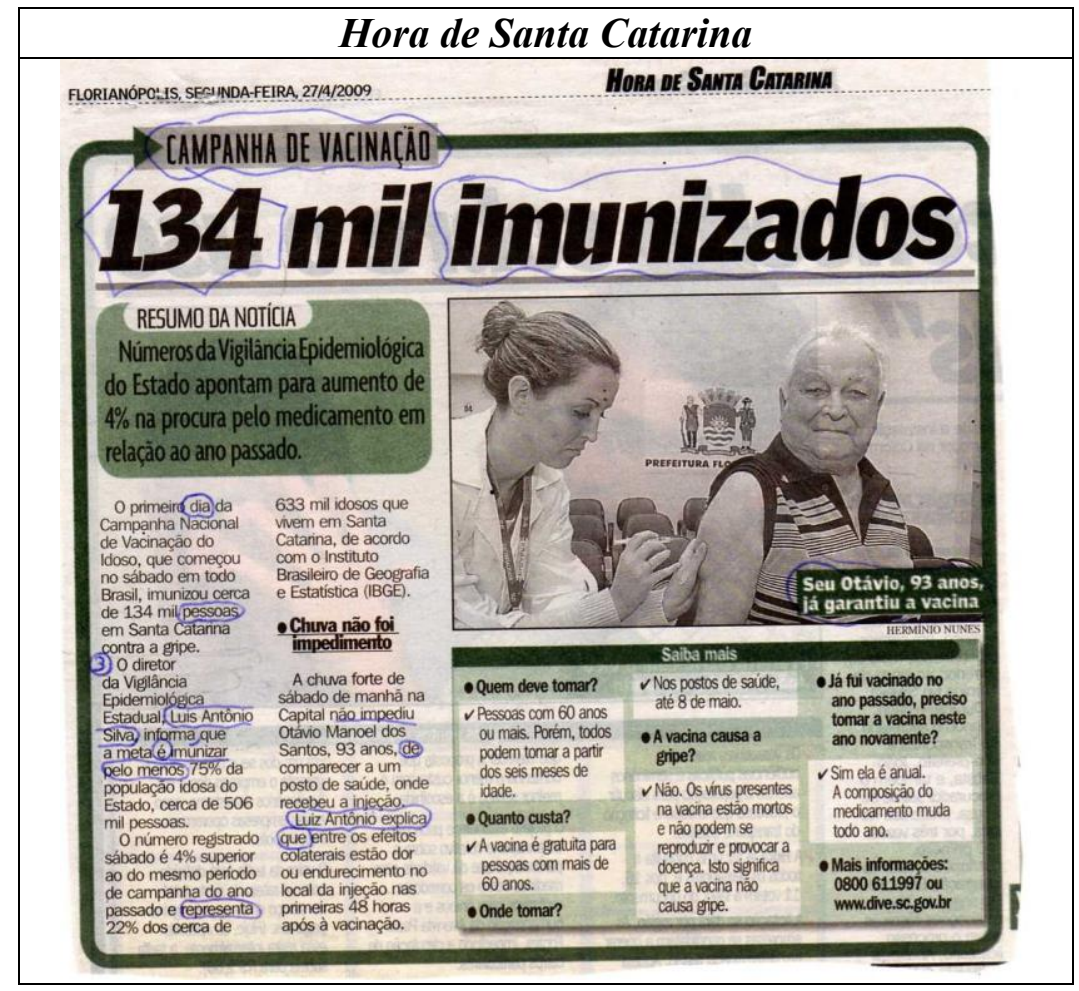

Work. pap. linguíst., 13(3): 21-44, Florianópolis, out.dez,2012 


\section{CONSIDERAÇÕES FINAIS}

Tendo como base o exposto até aqui, entendemos que ao produzir textos noticiosos os jornais Diário Catarinense e Hora de Santa Catarina intentam em suas páginas acomodar uma posição de sujeito-leitor em cada veículo de modo distinto. Isso é possível levando em consideração que cada projeto editorial antevê um leitor virtual para suas formulações linguísticas no que concerne ao ato de reportar acontecimentos.

No entanto, assinalamos que a relação discursiva entre leitor, texto e aquele que escreve é conflituosa e complexa. Ela não se dá de forma estruturada e absoluta no que concerne ao papel dos três elementos apontados, pois, em princípio, quem escreve (nesse caso o redator/repórter/jornalista) não possui um poder totalitário em relação ao processo de significação de um texto; o texto concentra uma pluralidade significativa, acarretando visões múltiplas ao leitor e, por isso, impossível de não ser de caráter polissêmico; e o leitor está para além de uma previsibilidade na identificação dos sentidos passíveis de proposição. Tendo isso em vista, a tríade autor, texto e leitor, segundo a Análise do Discurso, configurase fundamental, mas limitados em seus repertórios, dependendo um do outro para a realização de fim admissível - autor e leitor em constantes interlocução, e texto mediando essa relação.

Consideramos ainda que o implícito, em um texto, é tudo aquilo que não está visível numa leitura apenas de decodificação da materialidade linguística. Os contextos situacionais de produção e de interpretação (leitura) são inerentes à abrangência do processo de significar. Conhecer ou não contextos específicos pode levar o leitor a deixar de percorrer certos caminhos de interpretação, levando-o, provavelmente, a outros. No tangente à intertextualidade, o importante é o reconhecimento de um texto dentro de outro, realizando, portanto, conexões que subsidiam o discurso. Ou seja, o já dito instaura-se no dito possibilitando esse novo dizer, uma relação direta com a memória (o interdiscurso). Ou, se preferirmos, ocorre um diálogo entre o texto e outros (textos). O implícito e a intertextualidade aparecem intimamente relacionados pelo fato de que tanto um quanto o outro podem não estar em evidência, mas ocultos num plano extralinguístico.

Existe ainda uma relação entre o lugar social dos interlocutores e a produção de sentido dos textos. Essa relação está entrelaçada na "relação de poder" e tem por princípio norteador a posição que o autor ocupa ao desenvolver um texto, bem como, considera a posição do leitor que, de fato, irá ler esse mesmo texto. Ponderando essa afirmação, o resultado, a consequência, o efeito ou o produto significativo de um texto está profundamente

Work. pap. linguíst., 13(3): 21-44, Florianópolis, out.dez,2012 
relacionado com a disposição que o sujeito, sócio-historicamente inserido em particulares contextos, realiza.

Quando se fala em determinações históricas, isso se refere aos momentos específicos, com sujeitos em posições também específicas e, logo, as leituras ou construções de significados se darão conforme o modo como esses sujeitos estiverem dispostos no seu tempo, no interior dos quais as possibilidades de significações decorrerão dessas condições de produção. Em vista disso, a leitura, entendida como compreensão de particulares sentidos, será inteligível ou não. Vejamos, por exemplo, a leitura de um texto bíblico, sem remetê-la para uma determinada época e sem considerar inúmeras singularidades históricas desse tempo seria bastante difícil assimilar ou aceitar os possíveis sentidos. É de se verificar, também, que, dependendo do lugar/espaço, a percepção de mundo, inclusive considerando a situação histórica, econômica, cultural, etc., pode afetar a formulação de significados para um discurso e assim fomentar efeitos de sentidos diversos daqueles previstos.

Nesse sentido, uma análise, como a que foi proposta neste trabalho, pressupõe pensar na leitura como compreensão dos enunciados, historicamente postos em evidência, considerando a complexa relação entre autor, texto e leitor. Tudo isso vinculado tanto ao que está posto num texto como aos elementos que sobram (implícito) e, ainda, às relações de intertextualidade, cujo significado remete à memória tanto dos que produzem determinadas informações jornalísticas quanto aos sujeitos leitores dessas informações.

Para finalizar, as pistas contidas nos enunciados para a apreensão do(s) sentido(s) nos jornais alisados, por meio de cotejamento, serviram para a compreensão da produção de diferentes posições de sujeito-leitor. A análise aponta que os jornais $D C$ e Hora apresentam características semelhantes quanto ao processo de veiculação de suas informações. No entanto cada veículo se relaciona com seu público alvo de maneiras distintas através do uso da linguagem e no modo de produção de textos noticiosos. No Diário Catarinense há o predomínio da variante culta da língua; predomínio da lingual verbal sobre a não verbal; menos apelo a imagens icônicas; menos uso de cores e os textos noticiosos são alçados pela função referencial, visando à pretensa objetividade jornalística. Por outro lado, o Hora faz uso de uma linguagem menos formal; o texto é construído de forma hibrida, fazendo-se valer do uso recorrente de recursos imagéticos (desenhos e fotos); uso variado de cores; e a linguagem utilizada é passível de valoração. Isso acarreta na construção de diferentes posições dos respectivos leitores em relação às informações transmitidas, pois se valendo de 
estratégias enunciativas, esses jornais marcam, ideologicamente, os leitores do $D C$ como sendo mais letrados em relação aos do Hora.

\section{REFERÊNCIAS}

FOLHA DE SÃO PAULO. Manual de Redação. 2. ed. São Paulo: Folha de São Paulo, 2001.

FOUCAULT, Michel. A Arqueologia do Saber. 7. ed., Rio de Janeiro: Forense Universitária, 2004.

MACHADO, Márcia Benetti \& JACKS, Nilda. O discurso jornalístico, Brasília: Compós, 2001.

MAINGUENEAU, Dominique. Análise de textos de comunicação. São Paulo: Cortez, 2001.

ORLANDI, Eni [1988]. Discurso e Leitura. São Paulo: Cortez, 2006 . Análise de discurso: princípios e procedimentos. Campinas, SP: Pontes, 2003. . Discurso e texto: formulação e circulação dos sentidos. Campinas SP: Pontes, 2005. . As formas do silêncio: no movimento dos sentidos. São Paulo: Unicamp, 2007.

PÊCHEUX, Michel. Semântica e discurso: uma crítica à afirmação do óbvio. Campinas: Editora da Unicamp, 1988.

PINTO, Milton José. Comunicação e discurso: introdução à análise do discurso. São Paulo: Hacker Editores, 2002.

\section{REFERÊNCIAS DO CORPUS}

Diário Catarinense: exemplares datados de $1^{\circ}$ de maio a 30 de junho de 2009.

Hora de Santa Catarina: exemplares datados de $1^{\circ}$ de maio a 30 de junho de 2009. 